\title{
Severe symptomatic hyponatremia during citalopram therapy - a
}

\section{case report}

\author{
Guillermo Flores*, Santiago Perez-Patrigeon, Carolina Cobos-Ayala and \\ Jesus Vergara
}

\author{
Address: Department of Internal Medicine, Hospital de Especialidades del Centro Médico Nacional Siglo XXI, Instituto Mexicano del Seguro Social. \\ Mexico City, Mexico \\ Email: Guillermo Flores* - gmf368@yahoo.com; Santiago Perez-Patrigeon - syago@prodigy.net.mx; Carolina Cobos- \\ Ayala - carocobos26@hotmail.com; Jesus Vergara - vergara7@msn.com \\ * Corresponding author
}

This article is available from: http://www.biomedcentral.com/l47I-2369/5/2

(c) 2004 Flores et al; licensee BioMed Central Ltd. This is an Open Access article: verbatim copying and redistribution of this article are permitted in all media for any purpose, provided this notice is preserved along with the article's original URL.

\begin{abstract}
Background: Hyponatremia secondary to the syndrome of inappropriate secretion of antidiuretic hormone is an uncommon complication of treatment with the new class of antidepressant agents, the selective serotonin reuptake inhibitors. The risk of hyponatremia seems to be highest during the first weeks of treatment particularly, in elderly females and in patients with a lower body weight.

Case Presentation: A 6I-year-old diabetic male was admitted to the hospital because of malaise, progressive confusion, and a tonic/clonic seizure two weeks after starting citalopram, $20 \mathrm{mg} / \mathrm{day}$. On physical examination the patient was euvolemic and had no evidence of malignancy, cardiac, renal, hepatic, adrenal or thyroid disease. Laboratory tests results revealed hyponatremia, serum hypoosmolality, urine hyperosmolarity, and an elevated urine sodium concentration, leading to the diagnosis of inappropriate secretion of antidiuretic hormone. Citalopram was discontinued and fluid restriction was instituted. The patient was discharged after serum sodium increased from 124 $\mathrm{mmol} / \mathrm{L}$ to $134 \mathrm{mmol} / \mathrm{L}$. Two weeks after discharge the patient denied any new seizures, confusion or malaise. At that time his serum sodium was $135 \mathrm{mmol} / \mathrm{L}$.

Conclusions: Because the use of serotonin reuptake inhibitors is becoming more popular among elderly depressed patients the present paper and other reported cases emphasize the need of greater awareness of the development of this serious complication and suggest that sodium serum levels should be monitored closely in elderly patients during treatment with citalopram.
\end{abstract}

\section{Background}

Hyponatremia secondary to the syndrome of inappropriate secretion of antidiuretic hormone (SIADH) is an uncommon complication of treatment with the new class of antidepressant agents, the selective serotonin reuptake inhibitors (SSRIs) $[1,2]$. Estimations of the occurrence of hyponatremia during treatment with SSRIs range between
$0.5 \%$ and $25 \%$, and the risk of hyponatremia seems to be greatest during the first weeks of treatment with SSRI, in the elderly, in female patients and in patients with lower body weights $[3,4]$. However, severe consequences of hyponatremia caused SSRIs, such as tonic/clonic seizure, have not been reported. We describe the case of a 61-year- 
old male with tonic/clonic seizure caused by SSRIinduced hyponatremia

\section{Case Presentation}

We recently saw a 61-year-old male referred to us because of a 3-day history of malaise, progressive confusion, and a tonic/clonic seizure. Two weeks before, he had been started on a regimen of citalopram $20 \mathrm{mg}$ at bedtime. The patient and his wife reported that he became progressively confused, lethargic and had difficulty performing simple tasks. He is a type 2 diabetic treated with metformin 500 mg twice daily and glyburide $2.5 \mathrm{mg}$ once daily. Upon admission, the patient was afebrile with normal vital signs. He appeared euvolemic without evidence of congestion or dehydration. Neurologic examination was normal except for decreased strength on lower extremities. Significant laboratory findings included sodium of $124 \mathrm{mmol} /$ $\mathrm{L}$ (136-145 mmol/L), potassium of $4.3 \mathrm{mmol} / \mathrm{L}$ (3.5-4.5 $\mathrm{mmol} / \mathrm{L})$, chloride $86 \mathrm{mg} / \mathrm{dL}(98-106 \mathrm{mmol} / \mathrm{L})$, blood urea nitrogen of $3.2 \mathrm{mmol} / \mathrm{L}(3.6-7.1 \mathrm{mmol} / \mathrm{L})$, creatinine $79.56 \mu \mathrm{mol} / \mathrm{L}(<133 \mu \mathrm{mol} / \mathrm{L})$, glucose of 10.49 $\mathrm{mmol} / \mathrm{L}(4.2-6.4 \mathrm{mmol} / \mathrm{L})$, a uric acid of $150 \mu \mathrm{mol} / \mathrm{L}$ $(150-480 \mu \mathrm{mol} / \mathrm{L})$ and a serum osmolarity of $263 \mathrm{mosm} /$ $\mathrm{L}$ (285-295 mOsm/L). Urine sodium and urine osmolarity were elevated, $141 \mathrm{mEq} / \mathrm{L}$, and $400 \mathrm{mosm} / \mathrm{L}$, respectively. A CT of the head and an EEG were both normal. An AM cortisol level, thyroid-stimulating hormone (TSH) and free thyroxine levels were within normal limits. Results of a urine toxicology screen revealed no presence of ethanol or recreational drugs. A citalopram pill count confirmed compliance with the drug regimen without evidence of overdose.

A diagnosis of SIADH was made based on clinical euvolemia in the presence of hyponatremia with a urine osmolarity and sodium that were inappropriately high. Normal renal, thyroid and adrenal function with relative hipouricemia, all supported SIADH. Extensive investigations ruled out malignancy, pulmonary, hepatic cardiac or renal disease or any other known causes of SIADH.

On the day of admission, citalopram was discontinued and the patient was treated with 2 liters of intravenous $0.9 \%$ sodium chloride, phenytoin $(5 \mathrm{mg} / \mathrm{kg})$, and subcutaneous insulin. Approximately 24 hours after admission the patient's serum sodium increased to $129 \mathrm{mmol} / \mathrm{L}$ (136-145 mmol/L) and the chloride increased to 89 $\mathrm{mmol} / \mathrm{L}$ (98-106 $\mathrm{mmol} / \mathrm{L})$, thereafter, fluids were restricted to $1200 \mathrm{ml} /$ day. His mental status improved over the next 48 hours. Five days after admission serum sodium was $134 \mathrm{mEq} / \mathrm{L}(136-145 \mathrm{mmol} / \mathrm{L})$ and serum chloride was $99 \mathrm{mmmol} / \mathrm{L}$ (98-106 mmol/L). Patient was fully alert, had no more seizures and was subsequently discharged. At this time phenytoin treatment was stopped.
A follow up serum sodium three weeks after discharge was $135 \mathrm{mmol} / \mathrm{L}$ (136-146 mmol/L).

This patient's seizures appear to have been induced by hyponatremia that was secondary to SIADH, a diagnosis that is supported by the low serum sodium concentration, concentrated urine, and clinical evidence of euvolemia. The laboratory values and history were inconsistent with a diagnosis of psychogenic polydipsia. The finding of SIADH secondary to citalopram use may reflect dysregulation of serotonergic control of ADH release or metabolism. Experimental evidence in rodents has demonstrated the presence of serotonin's neurons in the hypothalamic supraoptic nucleus, which is where the $\mathrm{ADH}$ prohormone is synthesized[5]. Other studies suggest that serotonin may be involved in the regulation of ADH release[6]. The occurrence in this case of a seizure secondary to SIADHassociated hyponatremia suggests a possible mechanism for citalopram-induced convulsions and corroborates previous reports of citalopram-induced SIADH.

\section{Conclusions}

The present case and others previously reported, emphasize the need for greater awareness of the development of this serious and potentially fatal complication in association with citalopram therapy. Review of the present and previous cases has shown that the onset of citalopraminduced hyponatremia or SIADH ranges from 6 to 20 days after the therapy has been started [7-16]. Potential risk factors for SIADH due to citalopram included advanced age, female gender, concomitant use of medications known to cause SIADH or hyponatremia, and possibly, higher citalopram doses $[7,8,17]$. Therefore, a high level of suspicion, close and careful monitoring of serum sodium concentration particularly in elderly patients during the first month of therapy with citalopram may reduce the incidence of this serious and likely, not rare, adverse effect.

Although information is not conclusive, other SSRI's should also be avoided if treatment with an antidepressant had to be restarted in patients with past medical history of hyponatremia or SIADH induced by citalopram $[17,18]$.

\section{Competing interests}

None declared.

\section{Author's contributions}

GF was the attending physician and wrote the paper; SP is a fourth year resident in internal medicine that participated in the care of the patient; CC-A is second year resident in internal medicine that participated in the care of the patient; JV is a third year resident in internal medicine 
that participated in the care of the patient. All authors read and approved the final manuscript.

\section{Acknowledgements}

Written consent was obtained from the patient and his wife for publication of the study

\section{References}

I. Spigset O, Hedenmalm K: Hyponatremia in relation to treatment with antidepressants: a survey of reports in the World Health Organization database for spontaneous reporting of adverse drug reactions. Pharmacotherapy 1997, I 7:348-352.

2. Woo MH, Smythe MA: Association of SIADH with selective serotonin reuptake inhibitors. Ann Pharmacother 1997, I I:348-352.

3. Bouman WP, Pinner G, Johnson H: Incidence of selective serotonin reuptake inhibitor (SSRI) induced hyponatremia due to the syndrome of inappropriate antidiuretic hormone (SIADH) secretion in the elderly. Int J Geriatr Psychiatry 1998, I3:12-15.

4. Wilkinson TJ, Begg FJ, Winter AC, Sainsbury R: Incidence and risk factors for hyponatremia following treatment with fluoxetine or paroxetine in elderly people. Br J Clin Pharmacol 1999, 47:2II-2I7.

5. Vacher CM, Fretier P, Creminon C, Calas A, Hardin-Pouzet H: Activation by serotonin and noradrenaline of vasopressin and oxytocin expression in the mouse paraventricular and supraoptic nuclei. J Neurosci 22: 1513-22.

6. Jorgensen H, Riis $M$, Knigge $U$, Kjaer A, Warberg J: Serotonin receptors involved in vasopressin and oxytocin secretion. J Neuroendocrinol 2003, I 5:242-249.

7. Fisher A, Davis M, Croft-Baker J, Purcell P, McLean A: Citalopraminduced severe hyponatraemia with coma and seizure. Case report with literature and spontaneous reports review. Adverse Drug React Toxicol Rev 2002, 21 : 179-187.

8. Barclay TS, Lee AJ: Citalopram-associated SIADH. Ann Pharmacother 2002, 36: I558-I563.

9. Bourgeois JA, Babine SE, Bahadur N: A case of SIADH and hyponatremia associated with citalopram. Psychosomatics 2002 , 43:24I-242.

10. Hull M, Kottlors M, Braune S: Prolonged coma caused by low sodium and hypo-osmolarity during treatment with citalopram. J Clin Psychopharmacol 2002, 22:337-338.

II. Odeh M, Beny A, Oliven A: Severe symptomatic hyponatremia during citalopram therapy. Am J Med Sci 200I, 32 I:I59-I60.

12. Riquelme A, Mendez F, Ortiz AM, Muller H, Campos C, Rocha V, Valdivieso $A$ : Severe and recent hyponatremia and hypokalemia associated to the use of hydrochlorothiazide, enalapril and citalopram. Clinical case. Rev Med Chil I999, I 27: I 223-I228.

13. Pradalier A, Devars du Mayne JF, Barzegar C, Vincent D: Hyponatremia and probable inappropriate secretion of antidiuretic hormone due to citalopram. Therapie 1998, 53:600-602.

14. Spigset O, Adielsson G: Combined serotonin syndrome and hyponatraemia caused by a citalopram-buspirone interaction. Int Clin Psychopharmacol 1997, I 2:61-63.

15. Christensen O, Sorensen HA, Almdal TP: Adverse effects of selective serotonin uptake inhibitors. Hyponatremia caused by Schwartz-Bartter syndrome. Ugeskr Laeger 1996, I 58:6920-6922.

16. Voegeli J, Baumann P: Inappropriate secretion of antidiuretic hormone and SSRIs. Br J Psychiatry 1996, I 69:524-525.

17. Arinzon ZH, Lehman YA, Fidelman ZG, Krasnyansky II: Delayed recurrent SIADH associated with SSRIs. Ann Pharmacother 2002, 36: II75-II57.

18. Kirby D, Ames D: Hyponatraemia and selective serotonin reuptake inhibitors in elderly patients. Int J Geriatr Psychiatry 200 I, I 6:484-493.

\section{Pre-publication history}

The pre-publication history for this paper can be accessed here: http://www.biomedcentral.com/1471-2369/5/2/prepub 